\title{
Las cartas arameas de Bar Kokba: texto, traducción y comentario
}

\author{
Carlos Alonso Fontela y Juan José Alarcón SAInz * \\ Universidad Complutense, Madrid
}

Bar Kokbba es un sobrenombre por el que se conocía al líder de Israel que combatió contra el Imperio Romano durante la guerra que tuvo lugar en tiempos del emperador Adriano, entre los años 132 y 135 d.C. Este apodo significa, literalmente, «el hijo de la estrella», y se trata de un juego de palabras realizado a partir del que ahora sabemos que era su verdadero apellido, Bar Kôsiba. En efecto, Bar Kôk $\underline{b} \hat{a}^{\prime}$, «el hijo de la estrella», parece ser una alusión al pasaje bíblico de Núm 24, 17 b («... ha salido una estrella -kôkab-de Jacob, y ha surgido un gobernante de Israel...») del que, además, se hacía una interpretación mesiánica. Por cierto, tras los desastres de la guerra, los detractores de Bar Kôsiba hacían otro juego de palabras muy diferente y le llamaban Bar Kôzî̉bâ', «el hijo de la mentira», es decir «el mentiroso» ${ }^{1}$.

De este personaje, Simón bar Kôsiba, se tenían noticias vagas, cuando no abiertamente legendarias, en fuentes judías (Talmud y Midraš Lamentaciones

* calonsof@filol.ucm.es,jjalarco@filol.ucm.es

1 Véase Y. YADIn, Bar-Kokhba. The Rediscovery of the Legendary Hero of the Last Jewish Revolt against Imperial Rome (Jerusalem, Tel Aviv, Haifa 1978). Entre la numerosa bibliografía reciente merece destacarse B. IsAAC and A. OPPENHEIMER, «The Revolt of Bar Kokhba: Ideology and Modern Scholarship», JJS 36 (1985), págs. 33-60; R. G. MARKs. The Image of Bar Kokhba in Traditional Jewish Literature: False Messiah and National Hero (University Park, Penn. 1994); M. Mor, «The Bar-Kokhba Revolt and Non-Jewish Participants», JJS 36 (1985), págs. 200-209; A. REINHARTZ, «Rabbinic Perceptions of Simeon Bar Kosiba», JSJ 20 (1989), págs. 171-94; y R. Freund and R. ARav, «Return to the Cave of the Letters. What Still Lies Buried?», BAR 27 (2001), págs. 24-39. 
Rabbah) y en escritores cristianos (Eusebio, quien cita a Justino, y Jerónimo); pero, salvo las breves inscripciones en escritura paleo-hebrea de algunas monedas, que durante mucho tiempo fueron erróneamente atribuidas a Simón Macabeo, no se disponía de ninguna documentación judía contemporánea a esa guerra hasta que se produjo lo que podríamos llamar la segunda fase de los espectaculares descubrimientos del Mar Muerto.

Estos nuevos descubrimientos se produjeron a principios de la década de los años cincuenta del pasado siglo XX, en la ribera occidental del Mar Muerto, pero no en la zona de Qumrán, sino más al sur, en Wadi Murabba ât, donde los beduinos ta'amireh, animados por el lucro que les había producido la venta de manuscritos procedentes de Qumrán a finales de los años cuarenta, se dedicaban a explorar y excavar las cuevas de los demás acantilados de los angostos valles o «wadis» cercanos al Mar Muerto.

Como resultado de esa búsqueda de restos arqueológicos, en octubre de 1951 los beduinos ofrecieron directamente al Museo Rockefeller de Jerusalén Oriental, a la sazón bajo gobierno jordano, la venta de fragmentos de manuscritos procedentes de esas excavaciones clandestinas.

Asimismo, en noviembre de 1951, por medio de un intermediario de Belén, el famoso Khalil Iskander Shahin, más conocido por el apodo de Kando, se pusieron a la venta nuevos documentos, algunos de los cuales fueron adquiridos por R. de Vaux en diciembre de ese mismo año y, otros, en enero del 1952. Entre estos últimos, una carta en hebreo de «Simón ben Kosiba a Jesús ben Galgula y a la gente del fuerte» dio la clave para situar estos documentos en la época del legendario Bar/Ben Kokbba/Koziba (132-135 d.C.)

Estas circunstancias atrajeron el interés de los arqueólogos del Museo Arqueológico Palestino, del Departamento de Antiguedades de Jordania y de la Escuela Bíblica de Jerusalén, quienes, finalmente, pudieron explorar sistemáticamente cuatro cuevas de Wadi Murabba' ât, entre el 21 de enero y el 1 de marzo de $1952^{2}$.

Sus laboriosos trabajos proporcionaron restos arqueológicos de diversas épocas: Época Romana, Edad del Hierro (s. VIII-VII a.C.), Bronce Medio (ca. 2.250 a.C.), y Calcolítico (finales del cuarto milenio). Asimismo, se

2 Véase también P. Benort, et al., Les Grottes de Murabba' ât. Discoveries in the Judaean Desert. II: Texte (Oxford 1961). 
encontraron textos hebreos, arameos, griegos, latinos y árabes depositados por gentes que en distintas épocas encontraron refugio provisional en las grutas. De entre esos textos, es de destacar la correspondencia en hebreo encontrada en un archivo de documentos varios pertenecientes a Jesús ben Galgula, lugarteniente de Simón ben Kôsiba en la zona de Herodión.

Como quiera que, pese a la excavación arqueológica de Wadi Murabba'ât, los beduinos ta'amireh siguiesen llevando al mercado de antigüedades de Jerusalén Oriental documentos similares «de procedencia desconocida», los arqueólogos del Departamento de Antigüedades de Israel sospecharon que se podrían estar realizando excavaciones clandestinas en su territorio, lo que se demostró cierto en una exploración arqueológica realizada en la zona de En-Guedi, más concretamente en los accesos y las cuevas de Náhal Héver, a finales de 1953, seguida, en 1955, de otra expedición a los lugares más inaccesibles de la misma zona. En la mayoría de los lugares se detectó la actividad previa de los beduinos. Los arqueólogos encontraron restos de los campamentos romanos que sitiaban algunas de las cuevas, y, en el interior de las grutas, los restos de cerámica encontrados proporcionaron un marco cronológico similar al de Wadi Murabba ât (esto es, del Calcolítico a la Época Romana).

A finales de 1959, volvieron a aparecer en el mercado de Jerusalén Oriental otros documentos parecidos «de procedencia desconocida», pero que parecían provenir de Náhal Se'elim, al sur de Náḥal Héver y al norte de Masada, lo que dio lugar a una rápida expedición israelí a principios de 1960, seguida, en marzo de ese mismo año, 1960, por una gran operación arqueológica en toda la zona de cuevas desde Masada a En-Guedi a cargo del Departamento de Antigüedades de Israel y de la Universidad Hebrea, con apoyo del Ejército.

La zona de Náḥal Ḥéver, que estaba a cargo de Y. Yadin, proporcionó en la llamada Cueva de las Cartas (Cave of Letters, Locus 7) un conjunto de quince cartas o despachos militares de Simón bar Kokbba (P. Yadin 49-63) en arameo (9), hebreo (4) y griego (2). Se trataba de documentos cuidadosamente empaquetados y escondidos en una grieta-Locus 7- de la parte más interior -Sala $\mathrm{C}$ - de esa gruta por refugiados judíos procedentes de la vecina ciudad de En-Guedi, que, asediados por los romanos hacia el año 135 d.C., ocultaron lo mejor que pudieron sus pertenencias antes de morir. 
Gracias a esta nueva documentación sabemos ahora que el apodado Bar-Kokbba se llamaba en realidad Simón bar Kosiba. La vocalización exacta de su apellido se conoce por uno de los documentos en griego ${ }^{3}$ (Khôsiba en P. Yadin 59, lín. 2).

La mayoría de las cartas de Náḥal Héver descubiertas y publicadas por el equipo de Y. Yadin se supone que fueron dirigidas en la última fase de la guerra directamente desde el frente, que estaba apoyado en la vertiente occidental de los Montes de Judea, a una zona de la retaguardia controlada desde la ciudad de En-Guedi, en la ribera occidental del Mar Muerto. En cambio, algunas cartas relacionadas con la recogida de ramas de sauce y mirto para la celebración de la fiesta religiosa de Sukkôt o de los Tabernáculos, habrían llegado indirectamente a EnGuedi, tras haber pasado primero por una posición intermedia, Qiryat 'Arbayya ( $c f$. IX Bar Kosiba = P. Yadin 57, lín. 1), o, como podría ser el caso de las redactadas en griego, habrían sido remitidas directamente a En-Guedi desde esa posición intermedia. Es de destacar que en estas cartas, además de las cuestiones más propiamente militares, como son los asuntos de intendencia, logística, y de disciplina, se manifiesta un gran interés por asuntos religiosos.

Al año siguiente, en marzo de 1961, prosiguieron los trabajos con nuevos hallazgos de documentos en otros lugares de la misma Cueva de las Cartas (Locus 61): Un conjunto de seis papiros de carácter legal (P. Yadin 42-46), un papiro guardado en el interior de una caña hueca (P. Yadin 47) y un rollo de cuero, desgraciadamente sin utilizar (P. Yadin 48). Otro conjunto distinto, pero depositado en la misma época, es el llamado archivo de Babatha, formado por 35 papiros (P. Yadin 1-35) de carácter legal en griego (17), en griego con partes en arameo judío palestinense o arameo nabateo (9), en arameo nabateo (6) y en arameo judío palestinense (3).

De entre todos estos materiales, nos ocuparemos en este artículo de las nueve cartas arameas ${ }^{4}$ del apodado Bar Kokbba, aunque su

3 Los textos hebreos y arameos se escribían con un mismo alfabeto que, por no representar las vocales de forma precisa, recibe el nombre de «consonántico».

4 Hay una carta más, P. Yadin 60, que se solía hacer constar como aramea, pero que últimamente se considera hebrea. En realidad, es muy difícil leer en ella algo seguro. Al final de la primera línea parece leerse $l-y h v n t n$, «a Yěhônatan», lo que puede ser tanto hebreo como arameo. Con muchas dudas parece que podría haber al final de la línea tercera un - $h m$, esto es un pronombre personal sufijado de 3 . $^{\text {a }}$ persona masculino plural terminado en mêm, 
verdadero apellido era Bar Kosiba, como hemos dicho anteriormente.

Es de advertir que, por razones didácticas, estas cartas las presentaremos de forma un tanto diferente en relación a la secuencia numérica que tienen en la colección denominada $\mathrm{P}$ (apyri) Yadin ${ }^{5}$, de modo que nuestro orden será el siguiente: I Bar Kosiba $=$ P. Yadin 53, II Bar Kosiba $=$ P. Yadin 50, III Bar Kosiba $=$ P. Yadin 54, IV Bar Kosiba $=$ P. Yadin 55, V Bar Kosiba = P. Yadin 56, VI Bar Kosiba = P. Yadin 58, VII Bar Kosiba = P. Yadin 63, VIII Bar Kosiba = P. Yadin 62, y IX Bar Kosiba = P. Yadin 57. Pese a esta, y otras licencias, que nos hemos tomado, queremos dejar bien claro que, por tener nuestra edición una finalidad eminentemente práctica, nadie interesado en los aspectos paleográficos de estas cartas puede ahorrarse la imprescindible consulta de la edición de Y. Yadin.

El arameo de estas cartas, que hay que datar entre los años 132 y el 135 d.C., es particularmente interesante, pues nos proporcionan una cronología absoluta, que es fundamental para los estudios comparatistas de dialectología aramea. Asimismo, por tratarse de textos apresurados y sin más pretensiones que servir de instrumento de comunicación entre el alto mando militar y sus subordinados en la retaguardia, el arameo en el que están redactados es un testigo de excepción del influjo de la lengua vulgar sobre la lengua literaria en la fase del arameo medio.

En el aspecto lingüístico cabría destacar el uso inconsecuente de las matres lectionis en general, y de la confusión entre la hề y el 'álef para indicar la vocal /a/ a final de palabra en particular. Resulta especialmente

en vez de en nûn, siendo esta mínima variación gráfica la que inclinaría la balanza del lado de los que consideran ahora que el texto es hebreo. En la línea quinta sólo parece segura la negación $v-l$ ', «y no», que, a falta de vocalización, lo mismo puede ser aramea que hebrea.

5 Y. YAdin, et al., The Documents from the Bar Kokhba Period in the Cave of Letters. Hebrew, Aramaic and Nabatea-Aramaic Papyri (Jerusalem 2002). Otras ediciones previas de textos en D. PARDEe, et al., Handbook of Ancient Hebrew Letters: A Study Edition (Chico, Calif. 1982) [se analizan algunas cartas en págs. 114-144); H. M. CotToN and A. YARDENI, Aramaic, Hebrew and Greek documentary texts from Nahal Hever and Other Sites, with an Appendix Containing Alleged Qumran Texts (The Seiyâl collection II) [= DJD 27] (Oxford 1997); J. Charlesworth, et al., Miscellaneous Texts from the Judaean Desert [= DJD 38] (Oxford 2000); A. YARDENI, Textbook of Aramaic, Hebrew and Nabataean: Documentary Texts from the Judaean Desert and Related Material (Jerusalem 2000). 
interesante la grafía característica del dialecto judeo-arameo palestinense de mater lectionis hề en lugar de 'álef para la terminación del «estado enfático»o artículo arameo. Así, por ejemplo, אגרתה = «la carta», «el mensaje» en IV Bar Kosiba = P. Yadin 55, lín. 2 y VII Bar Kosiba = P. Yadin 63, lín.5; pero es significativo que en una misma carta, III Bar Kosiba = P. Yadin 54, la palabra «el castigo» o «el escarmiento» sea escrita en la forma más literaria פרענותא, en lín. 7, y, en cambio, en la forma dialectal פרענותה, en lín. 13.

También se documenta la confusión entre sîn y sámek , indicio de que se está produciendo la evolución de ś > s. Así, por ejemplo, el apellido del líder Kosiba, presente en el encabezamiento de seis de estas cartas, aparece con las cuatro siguientes grafías: כוסבה (I Bar Kosiba = P. Yadin 53, III Bar Kosiba = P. Yadin 54, V Bar Kosiba = P. Yadin 56), כוסבא (VII Bar Kosiba = P. Yadin 63), כשבה (II Bar Kosiba = P. Yadin 50), y כושבה (IV Bar Kosiba = P. Yadin 55). Como puede verse, predomina la scriptio plena de la vav mater lectionis que indica la vocal /o/, así como la mater lectionis hê' en lugar de 'álef para la vocal /a/. Así mismo, predomina la sámek sobre la sîn. El predominio de la grafía sámek en este apellido es absoluto en los documentos hebreos de tipo diastrômata ${ }^{6}$, encontrados en Wadi Murabba'ât (Mur. 24, fragmentos B, lín.3, y C, lín. 3: כוסבא). También es habitual la grafía con 'álef

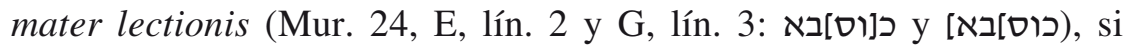
bien tenemos la mater lectionis hê' (כוסבה) en la carta hebrea Mur. 43, lín. 1. También los documentos legales hebreos de la Colección Yadin, que mencionan a Ben Kôseba, son constantes en el empleo de la grafía sámek y del 'álef mater lectionis (כוסבא P. Yadin 44, lín. 1 y 7, P. Yadin 45, lín. 2 y 13, P. Yadin 46, lín. 1), e igualmente, emplean la sámek los documentos legales arameos de la misma Colección, si bien no son constantes en el uso de las matres lectionis (כוסבא P. Yadin 42, lín. 1, pero כסבה en P. Yadin 43, lín. 2 y 7).

Más rara es la confusión entre šîn y sámek , que se podría explicar por influjo de un sistema fonológico extranjero (influjo del griego o, más

\footnotetext{
6 Diastrômata, es una palabra procedente del griego (dia = «hecho de», y strômata $=$ «mezcla») para un tipo de documento hecho de una miscelánea de contratos de arrendamiento agrícola. Es un plural neutro que pasó al latín, stromata, donde era sinónimo de miscellanea, «misceláneas», según R. DE Miguel, Nuevo Diccionario Latino-Español Etimológico (Madrid 1897, 11. a edición), pág. 885.
} 
posiblemente, del sustrato árabe de algún nabateo). Así el saludo סלם $($ salâm $)=$ «paz», en III Bar Kosiba $=$ P. Yadin 54, lín. 2, parece más bien árabe, porque lo correcto en arameo es שלם (šalâm > šlâm), que aparece en I Bar Kosiba = P. Yadin 53, lín. 5, V Bar Kosiba = P. Yadin 56, lín. 10, VI Bar Kosiba = P. Yadin 58, lín. 2 y IX Bar Kosiba = P. Yadin 57, lín. 6.

Hay un antropónimo, Bar Be/a'yan, que normalmente acaba en -an בר בעין en II Bar Kosiba = P. Yadin 50, lín. 2, V Bar Kosiba = P. Yadin 56, lín. 1, IX Bar Kosiba = P. Yadin 57, lín. 2, y, en griego, P. Yadin 52, lín. 2, Belaíanou), pero que en un caso aparece terminado en - $a h$, (בנר] בעיה en I Bar Kosiba = P. Yadin 53, lín.2). Esta evolución de -an $>a h$ nos parece un uso hipocorístico semejante al producido en la evolución del nombre de María (Maryah < Maryan $<$ Maryam).

Se da la pérdida o síncopa de la hêe en עלו>ה , עsobre él» (III Bar Kosiba = P. Yadin 54, lín. 16). También hay síncopa del 'álef en los verbos de las raíces ' ḥd, «coger» (III Bar Kosiba $=$ P. Yadin 54, lín. 4 y 16) y 'ty, «venir» (V Bar Kosiba = P. Yadin 56, lín. 6), así como en el sustantivo 'ătar, «lugar», precedido de la conjunción copulativa $v$-, «y», y de la preposición min, «de» asimilada $(ר)<$ ומ IV Bar Kosiba $=$ P. Yadin 55, lín. 3). Asimismo, se da la síncopa de la yôd en יל ל ל mano», «a mí poder» (II Bar Kosiba = P. Yadin 50, lín. 9).

La atenuación o apócope de la tav final radical de la palabra de origen hebreo šabbat, «sábado», que se da en II Bar Kosiba = P. Yadin 50, lín. 6 , podría deberse a que fuese entendida como morfema de femenino y se diese un caso de ultracorrección. En cualquier caso, este fenómeno está documentado en un 'ostrakon de Elefantina, y se da también en siríaco y en arameo talmúdico ${ }^{7}$.

Es habitual el prefijo hit- $(<* i t-)$ en las formas derivadas reflexivoreciproco-pasivas, lo que podría ser un caso de ultracorrección motivado por el paso en la forma causativa $h a f^{\prime} i l$ del prefijo hê' a 'álef $(* h a->$ 'a-). Asimismo, es notable la ausencia en las formas de prefijo hit- de la metátesis de la tav ante sibilante (I Bar Kosiba = P. Yadin 53, lín. 3 y III Bar Kosiba = P. Yadin 54, lín.6).

7 Cf. Y $\mathrm{ADIN}$, The Documents from the Bar Kokhba Period, pág. 96, en su comentario al mismo caso que se da en P. Yadin 7, línea 7, un documento arameo de donación. 
Hay un caso en IV Bar Kosiba = P. Yadin 55, lín. 3 en el que la preposición min, «de» aparece asimilada a la palabra siguiente (מומ > $>$, «y de (otro) lugar»), pero antes, en la misma línea, aparece sin asimilación, מן תקוע, «de Tecoa».

El pronombre relativo separado, $d \hat{\imath}$, es mucho más frecuente que el relativo prefijado, $d$-, en una proporción que, si no hemos contado mal, es de veinticuatro a dos; pero se da un caso en que aparecen las dos formas en la misma línea (V Bar Kosiba = P. Yadin 56, lín. 3, (די תדברון (...) דתיתון... «que conduciréis... que traeréis»).

\section{BAR KosIBA}

Esta carta, por su brevedad, y relativa sencillez, nos pareció la más adecuada para dar comienzo a nuestro estudio de las cartas arameas de Bar Kosiba. Su contenido se refiere a instrucciones del alto mando a la retaguardia para facilitar la misión de un agente.

Está en escritura cursiva «judía» estándar, sobre papiro.

\section{Bar Kosiba $=$ Yadin $53=$ Fitzmyer 55.}

\section{Traducción}

Carta de Šim‘ôn, hijo de Kôsibah. ¡Paz!

A Yěhônatan, hi[jo de] Be/a'yah. Todo lo que 'Elîša'

te diga, házse(lo); y esfuérzate

con él [en to]da acción.

¡Sigue bien!

\section{Texto}

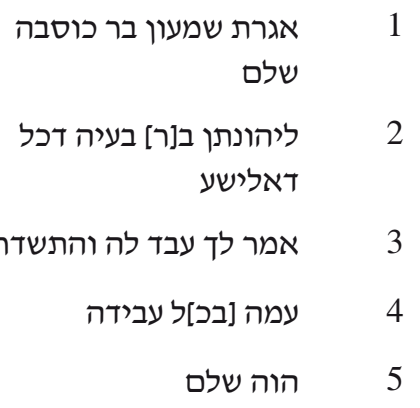




\section{Comentario}

\section{Lín. 1}

Šim 'ôn bar Kôsibah, comúnmente conocido como Bar Koḱbah, era el máximo dirigente judío durante la segunda gran guerra contra los romanos (132-134/5 d.C.), esto es, en tiempos del emperador Adriano (entre los años $16^{\circ}-18^{\circ} / 19^{\circ}$ de su reinado). La vocalización de su apellido se conoce por un documento en griego (Khôsiba). Aquí el texto consonántico tiene grafía sáme $\underline{k}$, pero en otros textos aparece escrito con śîn. Nótese también el uso de la mater lectionis hề' para indicar la /a/ final, lo que es característico del arameo judeo-palestinense no literario.

\section{Lín. 2}

El destinatario es Yěhônatan bar Be/a'yah. Aquí su apellido parece ser una forma hipocorística del Be/a' yan, que aparece en otros documentos. Este personaje, junto con Masabalah bar Šim ôn, eran los lugartenientes de Bar Kôsibah en En-Guedi. La vocalización de sus apellidos se conoce por la documentación griega (Be/aïanoû / Ma[s]abála). Todo lo que 'Elî̌ša'... lit. Que todo lo que (דכל ד דל 'Elîša'... El pronombre relativo prefijado $d$-, funcionaría aquí como una partícula introductoria al mensaje de la carta, pero no se puede mantener en traducción si se opta por traducir literalmente el imperativo siguiente, házse(lo).

\section{Lín. 3}

házse(lo), lit. hazle, haz para él, haz a favor de él, pero también se puede entender como hazlo.

... y esfuérzate... Nos encontramos ante un imperativo masculino singular de una forma hitpa' al de una raíz de primera sibilante, pero sin metátesis (חשתדר), משתדר). sic, por Igualmente, se da la ultracorrección típica del arameo judío de usar el prefijo hit-<ex 'it-. Aquí la raíz nos parece que sería $\check{s} d r$, con grafía šîn, que significa «esforzarse, trabajar», y también «enviar», pero sería posible que se tratase de una grafía śîn, escrita en lugar de una sámek , cuyo significado sería «arreglarse, organizarse, ponerse de acuerdo». Otra posibilidad que se ha apuntado es que podría tratarse de una alteración fonética de la raíz שדל, con cambio de la tercera radical $(1>$ r), y con el significado de «actuar»o «quedar bien», pero nos parece menos probable. 
Lín. 5

La fórmula de despedida iSigue bien!, se podría traducir más literalmente por ;Ten salud!

Este texto es el publicado con el $\mathrm{n}^{\circ} 55$ del Manual de J.A. Fitzmyer ${ }^{8}$, pero encontramos las siguientes variantes: En lín. 4 tiene: ' $m h[\cdots]$ bydeh, «con él $[\cdots]$ en su mano.»; en lín. 5 pone mater lectionis 'alef en $h v^{\prime}$, pero lo correcto nos parece la lectura arriba indicada, con la mater lecciones hêे.

\section{BAR KosIBA}

Esta carta, relativamente bien conservada, presenta algunas dificultades por lo que pensamos que son errores ortográficos debidos a una redacción apresurada. Trata de instrucciones a la retaguardia. Es de destacar la alusión al sábado y la preocupación por la protección del arbolado.

Está en escritura cursiva «judía» sobre papiro.

\section{Bar Kosiba $=$ Yadin $50=$ Fitzmyer 56.}

\section{Traducción}

Šim ôn, hijo de Kôśibah.

A Yěhônatan, hijo de Be'yan

y a Maśabalah, hijo de Šim'ôn

Me enviaréis a 'El'azar,

hijo de Hțh inmediatamente, antes del

sábado, y seréis cuidadosos con su(s)

producto(s)

y con el resto de todo(s) su(s) fruto(s).

$\mathrm{Y}$ (a) quienquiera que

\section{Texto}

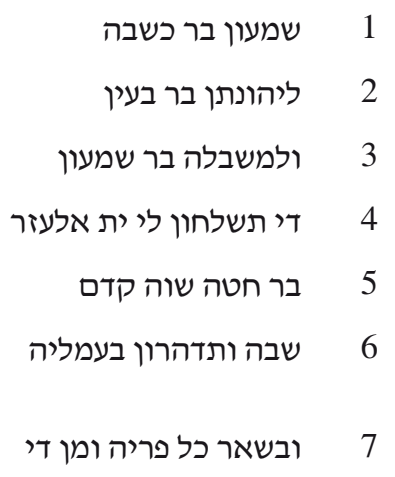

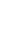

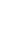
(1) 5

8 J.A. Fitzmyer y D.J. Harrington, A Manual of Palestinian Aramaic Texts (Second Century B.C. - Second Century A.D.) (Rome 1978), pág. 160. 


\section{Traducción}

os proteste sobre lo que así (se hace),

tú despáchamelo a mí, y yo (lo) castigaré.

El ganado, que no destruya

el arbolado. Y (a) quienquiera que

proteste, el castigo

será por tu parte abundante, pero (al)

plantel de ládano,

que no se le acerque nadie.

Šim 'ôn, hijo de Yĕhûdah

lo escribió

\section{Texto}

\begin{tabular}{|c|c|}
\hline יצחבנכן על די כדן & \\
\hline שגר לדי ואנה איתפרע & \\
\hline ובערה די לא יחרבן ית & \\
\hline אלנה ומן די יצחב פרענת & \\
\hline תהוה מנך רבה ולטמה & \\
\hline די לא יקרב בה אנש & \\
\hline שמעון בר יהודה & \\
\hline תבה & \\
\hline
\end{tabular}

\section{Comentario}

Lín. 1

El remitente, Šim 'ôn bar Kôśibah, con grafía śîn en el apellido.

Lín. 2 y 3

Los destinatarios son, en primer lugar, Yěhônatan bar Bela yan, y después Masabalah bar Šim 'ôn. Este Masabalah aquí con grafía śîn, parece haber sido el lugarteniente de Yěhônatan bar Be' yan, después del cual se le suele mencionar casi siempre.

Lín. 4.

Me enviaréis (די תשלחון) va precedido del pronombre relativo aislado $(d y)$ en función de partícula introductoria al mensaje de la carta. Ya hemos visto en I Bar Kosiba, lín. 2, el mismo uso del pronombre relativo prefijado $(d-)$.

Nótese el uso de ית (nota accusativi, o partícula que introduce el objeto directo) con el nombre propio de 'El' azar bar Hth, y en la lín. 10/11 con el nombre común «árbol»o «arbolado».

Lín. 6.

sábado, es la palabra hebrea שבת šabbat, que aquí aparece escrita שבת, šabbah, posiblemente por ultracorrección, por haberse considerado que la tav tercera radical era un morfema de femenino que debía atenuarse $-a t>-a ̂ h$. 
... y seréis cuidadosos (ותדהרון) -sic- debería ser ות>ו> דהרו), imperfecto 'itpe/a. de la raíz $z h r$.

Lín. 6 y 7.

... con su producto (7) y con ... su fruto, probablemente quiera decir «con sus haberes y ... sus ganancias.»

Lín. 8

צחב (cf. también lín. 11) se traduce por «protestar» siguiendo el significado del verbo árabe șahiba, «gritar, dar voces, alborotar.» ${ }^{9}$

Lín. 9

tú despáchamelo... Hay un cambio en la persona del verbo. A la vista de lo anterior, uno esperaría un «despachádmelo vosotros», pero nos encontramos con una segunda persona masculino singular del imperativo del verbo שגר. Lo hemos traducido por «despachar» en el sentido de «enviar con rapidez y sin contemplaciones», para intentar reflejar dos de las acepciones que este verbo tiene en su forma $\mathrm{pa}^{\prime} \mathrm{el}$, «correr, hacer correr» y «enviar». ... a mí, lit. «a mi mano/poder», לידי לדי לדי donde se habría producido la eliminación de la yôd primera radical por influjo de la vocal /i/ de la partícula (*liydî > lidî).

Lín. 10

El ganado que no destruya... se trata de un nombre colectivo, por lo que su verbo en arameo va en plural. Lit. «el ganado (es decir, las bestias) que no destruyan...».

Lín. 11

el arbolado, colectivo, $c f$. AB Dan 4,7 'îlân, «árbol».

Lín. 11 y 12

el castigo (12) será abundante por tu parte (lit. de ti) es una frase imprecisa. Nosotros pensamos que en este contexto parece indicar: «tú aplicarás un severo castigo (por ti mismo, sin remitirme la causa, a diferencia del supuesto mencionado anteriormente en la lín. 9)». Ahora bien, excelentes autores lo entienden en el sentido de que, «si alguien protesta, el castigo severo se te aplicará a ti», pero esto estaría en aparente contradicción con lo dicho antes, y con lo que se dice después. Así, pues, y pese a la reconocida autoridad de M. Sokoloff, que en su

\footnotetext{
9 Cf. F. Corriente, Diccionario Árabe-Español (Barcelona 1991), pág. 429.
} 
libro A Dictionary of Judean Aramaic, Jerusalem 2003, pág. 74, traduce «you will be severely punished», a nosotros nos parece que la palabra פרענו (po/ur'ânû, cf. TgJer 2,19), «paga, recompensa merecida» $\mathrm{y}$, por antífrasis, «castigo, escarmiento», cuando va acompañada de la raíz hvy en qal más min significa «castigar» en el sentido de que «el castigo será de tu incumbencia», «de ti será responsabilidad el darles su merecido». En cambio, se emplea la raíz ' $b d$ en 'itpe. más min para «ser castigado» («se hará de ti un escarmiento»). El mismo giro idiomático con ' $b d$ en qal más min significa «castigar $a$ alguien, hacer un escarmiento de alguien».

\section{Lín. 12}

pero (lit. «y») (al) plantel de ládano... Hemos traducido así la palabra לטמה, luțah, masc. sing. enfático con grafía hê', que en realidad parece ser la goma resinosa de uso cosmético y medicinal producida por una planta del género Cistus, especialmente de la Cistus ladanifer, que es la jara común castellana, y que en catalán es precisamente llamada estepa de làdan. En griego tenemos ládanon y lêdanon, en latín ladanum, y en castellano ládano. En árabe latîm y latîima es «perfume», y en hebreo loṭem «ungüiento». No es por incordiar, pero en siriaco la palabra luța' es «pistacho» («the pistachio nux»), con lo que el abanico de posibilidades se amplía un tanto. En cualquier caso, si atendemos a la protección del arbolado mencionada inmediatamente antes, tal vez haya que entender que se refiere a la plantación y no al producto.

Este texto se publicó en el Manual de Fitzmyer (nº 56, pág. 160) de forma muy abreviada: sólo las cinco primeras líneas y la primera palabra de la línea sexta, seguido de las líneas 14 y 15.

\section{BAR KOSIBA}

Esta carta presenta algunas dificultades por lo que pensamos que son errores ortográficos, debidos tal vez a un influjo nabateo y a una redacción apresurada. Diversas lecturas dudosas y lo conciso del mensaje aumentan el grado de dificultad de este texto. Su contenido se refiere a medidas económicas y disciplinarias.

Fue escrita en dos columnas paralelas sobre una tabla de madera que apareció deliberadamente fragmentada para adecuar su tamaño al del 
resto de los papiros plegados. El tipo de letra es, según la descripción de Yadin 2002, una versión no caligráfica y algo descuidada de la cursiva «judía» estándar.

III Bar Kosiba $=$ Yadin 54 = Fitzmyer 53.

\section{Traducción}

Šim ôn, hijo de Kôsibah, el jefe de Israel.

A Yěhônatan y a Masabalah. ¡Paz!

Inspeccionaréis

y cogeréis el trigo que trajo (?) Hannûn, (?)

hijo de Yišma"el. Me enviaréis de ello setenta (?)

(medidas de) una $s e^{\text {' }} a h$, y las pondréis con (una guardia de) seguridad,

pues se han producido robos. Si no (lo)

hacéis así, (sabed) que de vosotros un escarmiento

se hará. Al hombre, me lo enviaréis

con (una guardia de) seguridad.

(Respecto a) cualquier hombre de Tecoa que sea encontrado

entre vosotros, las casas en cuyo interior habiten ellos,

arderán, o yo haré de vosotros

\section{Texto}

Columna I

שמעון בר כוסבה הנסי על

ישראל ירון

2

תבחנון

3

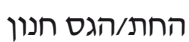

4

מנהן עין

5

באספליא

6

7

8

9

\section{Columna II}

וכול גבר תקועי די יתשכח

10

לותכן בתיה די אנון שרין

11

בגוהן יקדון ומנכן אעבד 


\section{Traducción}

un escarmiento. Y a Yěšûa ${ }^{\mathrm{c}}$,

el hijo del palmireno, (lo) cogeréis y me lo

despacharéis

a mí con (una guardia de) seguridad, y no dejéis de

coger la espada que lleva encima. Lo despacharéis.

Š̌̆mû' el, hijo de 'Ammî.

\section{Texto}

ית פרענותה וית ישוע

בר תדמריה תחדון תשגרון

לי באספליה ולא תבסרון

למחד ית סיפה די עלוי

תשגרון

שמואל בר עמי
15

13

14

16

17

\section{Comentario}

Lín. 1

El remitente, Šim 'ôn bar Kôsibah, con grafía sámek y hề en el apellido, recibe el título de «jefe (o «presidente», «príncipe», «líder»): de (lit. sobre) Israel». La palabra «jefe» (הנסי ha-nasî-sic- con sámek en lugar de śîn, y sin 'álef final), aunque está en un hebreo que no es muy clásico, lleva el inconfundible artículo determinado $h a$-.

Lín. 2

Los destinatarios son, en primer lugar, Yěhônatan (bar Be'yan), y después, Masabalah -con sámek- (bar Šim'ôn). La fórmula de saludo ¡Paz! סלם sělâm-sic- está escrita con sámek se trate de un posible influjo de la fonética griega de un judío helenista, o de la fonética árabe a través de un judío en contacto con los nabateos. Que el escriba era judío lo indicaría el hecho de que en la última línea aparece un nombre hebreo (Šěmû'el, hijo de 'Ammî). Inspeccionaréis... precedido del pronombre relativo aislado $(d y)$ en función de partícula introductoria al mensaje de la carta.

Lín. 3

y cogeréis..., se trata del verbo אחד con pérdida del 'álef tras la preformativa del imperfecto. Lo mismo ocurre infra, líneas 14 y 16 , ...el trigo... lit. «los trigos», ת חנטיא, con yât (nota accusativi) con un nombre común ( $c f$. infra líneas 8,13 y 16), חנטה, masc. sing. = «trigo», que, 
como en este caso, se usa también en plural. ... que trajo... es lectura dudosa (raíz אתי). También se ha propuesto leer: ... que depositó... (raíz נחת), у ... que saqueó..., lit. «... que devoró...» (raíz נגס).

... Hannûn, ... la mater leccionis parece ser una vav, pero no es de descartar que se trate de una yod.

\section{Lín. 4}

Me enviaréis (די תשלחון) va precedido del pronombre relativo en función de partícula introductoria al mensaje de la carta. Ya hemos visto lo mismo en II Bar Kosiba, lín. 4, y en I Bar Kosiba, lín. 2.

... setenta (?)... la cifra parece estar indicada por el nombre completo de letra 'áyin, cuyo valor numérico es 70. La se'ah es una medida de capacidad para áridos y líquidos que equivalía aproximadamente, según Flavio Josefo, a 1,5 modios latinos, unos 13 litros si damos para cada modio un valor de 8,75 litros. Dando, pues, a esta unidad de medida un valor de unos 13 litros, no se justifica, por lo escaso de la cantidad, la petición de que se envíe, como se dice en Yadin 2002, pág. 308, «... precisely (or: on time/here), one se'ah», y que se pongan bajo guardia (lit. «y las pondréis con seguridad»). Más bien parece que se ha de tratar de un envío relativamente importante, las setenta (medidas de) una $s e^{\prime} a h$, que proponemos, serían unos 910 litros.

con (una guardia de) seguridad... se trata de un préstamo griego 'asfáleia, que se puede traducir por «seguridad, firmeza, estabilidad»... Va precedido de la partícula aramea $b-$, «en, con, por»... y aparece aquí y en la lín. 9 con mater lectionis 'álef para representar la vocal /a/ final griega, lo que es más propio del arameo literario, y que no debe sorprender tratándose de lo que parece un cultismo griego evidente. Pero, con todo, en la lín. 15 se emplea la mater lectionis hêe', que es lo habitual en estas cartas y es más propio del arameo judeo-palestinense menos literario. No se es, pues, demasiado consecuente con la grafía de las matres lectionis.

Lín. 10

(Respecto a) cualquier hombre de Tecoa... lit. «Y todo hombre tecoíta...» La localidad de Tecoa se encuentra en Judea, a unos 9 kilómetros al sur de Belén. ... que sea encontrado... al igual que ocurría en I Bar Kosiba, lín. 3, tenemos aquí una forma '/hitpe. (cf. AB Dan 6,12) de una raíz de primera sibilante, pero sin metátesis. 
Lín. 11

las casas... בתיה masc. plur. enfático con grafía hêe’.

Lín. 12

arderán... i.e. «serán quemadas»; se trata de un imperfecto qal del verbo יקד con pérdida de la primera radical. ... $o$, lit. «y».

Lín. 13

... un escarmiento, פרענותה, fem. plur. enfático con grafía hêe', lit. «el castigo (ejemplar), el escarmiento».

Lín. 14

... del Palmireno, lit. תדמריה, «del Tadmorí», un gentilicio (masc. sing. en estado enfático con grafía $h \hat{e}$ ') formado a partir del topónimo Tadmor, que es el nombre semítico de la ciudad de Palmira.

Lín. 14 y 16

... despacharéis, hemos traducido por «despachar», en la acepción de «enviar deprisa», el verbo arameo שגר, que significa en forma $\mathrm{pa}^{\prime} \mathrm{el}$ «hacer correr» $\mathrm{y}$ «enviar». Intentamos, pues, recoger los dos matices del significado del verbo arameo, así como diferenciarlo en nuestra traducción de los verbos שדר y שלח, que también se usan en los textos de Bar Kosiba con el significado de «enviar».

Lín. 16

... la espada סיפה,, masc. sing. enfático con grafía hêe';... que lleva encima, lit. «... que (está) sobre él», עלוי >עלוהי.

Este texto fue publicado en el Manual de J. A. Fitzmyer $\left(\mathrm{n}^{\circ}\right.$ 53, pág. 158) de forma muy resumida, pues sólo proporciona el texto de las siguientes líneas: línea 1 y tres primeras palabras de la línea 2, tres últimas palabras de la línea 5, dos últimas palabras de la línea 6 , seguidas de la línea 7 completa y de la primera palabra de la línea 8 , tres primeras palabras de la línea 10 , dos últimas palabras de la línea 12 y dos primeras de la 13. Última palabra de la línea 13 seguida de las dos primeras de la 14, dos últimas palabras de la línea 15 , seguidas de las cinco primeras de la línea 16, y finalmente, la línea 17 completa. En este texto encontramos las siguientes variantes: Fitzmyer en su lín. 2, que, en realidad, es la 7 del documento tiene: $t^{\prime} b d v n$ por $t y$ ' $b d v n$ y en su línea 3, la 12 del documento lee $\boldsymbol{d}-m n-k n$ por $\boldsymbol{v}-m n-k n$. 
IV BAR KosIBA

Es un texto relativamente sencillo, salvo unas pocas lecturas dudosas. La carta se refiere a la captura de aquellas personas no autorizadas a residir en En-Guedi, con especial mención a los de Tecoa. Probablemente, se trataría de huidos del frente.

Está en escritura cursiva «judía» sobre papiro.

IV Bar Kosiba $=$ Yadin 55 = Fitzmyer 59.

\section{Traducción}

Šim ôn bar Kôśibah: A Yěhônatan

y a Masabala'. El mensaje (es) que (a)

cualquier

hombre de Tecoa o de otro lugar (no autorizado)

que (esté) entre vosotros, me los -sic- enviaréis a mí

con rapidez (?), porque si

no los enviáis, sabido

os sea que yo haré de vosotros

un escarmiento [.../¿destruidas?] sean las casas (que los acogen?)

\section{Texto}

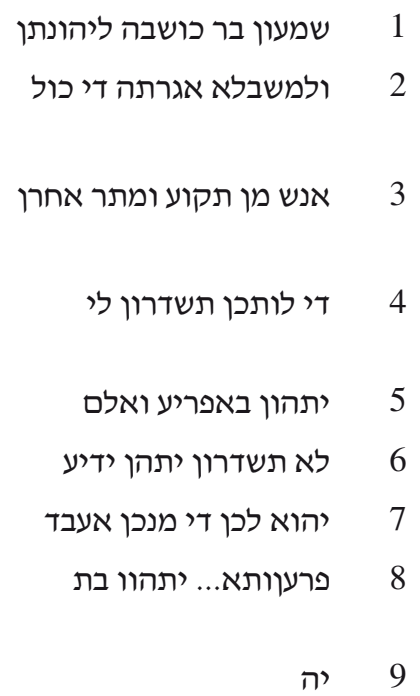

\section{Comentario}

Lín. 1

Kôśibah, con grafía śîn y hêe final.

Lín. 2

Masabalah, con śîn y 'álef final. El mensaje, lit. la carta, אגרתה, fem. sing. en estado enfático con grafía $h \hat{e}$ ', $c f$. A.B. 'iggartâ', préstamo del acadio egertu. 


\section{Lín. 2 y 3}

... cualquier hombre de Tecoa..., lit. «todo hombre de Tecoa». Sobre la represión contra estas personas tecuanas, y los que les den cobijo, véase supra, III Bar Kosiba = Yad 54, lín. 10.... o (lit. y), ... de otro lugar... מתר מאתר אחרן >-sic-pero según otra lectura menos probable, מתל ארזין, de Tel-'Arzîn.

\section{Lín. 5}

los -sic- en plural. Como puede verse, se usa el yât (nota accusativi, o partícula que introduce el objeto directo) con el pronombre personal sufijo de tercera persona masculino plural, aquí con grafía plena, si bien en la lín. 6 aparece con grafía defectiva יתהן y יתון.... con rapidez... es una lectura un tanto insegura, באפנריע, y la pêh no está del todo clara, $c f$. TgOnq., Neof. y PsJon. a Éx 32, בפריע, 8 , «con rapidez, rápidamente», «pronto», que traduce la palabra hebrea מהר maher. En Arameo Oficial aparece 'pry', si bien la lectura de la rêš es incierta ${ }^{10}$.

porque si... lit. «y si», conjunción copulativa prefijada a la partícula condicional אלם, aunque otros leen אם, pero el rasgo vertical de la lamed nos parece claro. En arameo posterior tenemos ' $I m l$ ', pero según $\mathrm{M}$. Sokoloff sólo en fuentes procedentes de Babilonia. Con todo, nosotros hemos encontrado 'Iml', como variante de 'Imly en diversos mss. del TgCant 4, 12. Asimismo, aparece en TgSal 106, 23 para traducir la partícula condicional negativa hebrea לולי, lûlê. Además, no debemos olvidar que 'Iml' aparece en hebreo mísnico (es bien conocido el aforismo de Abôt $3,2)$, por lo que no es extraño su uso en el arameo de estas cartas.

Lín. 6 y 7

... sabido os sea... lit. «conocido sea para vosotros», es un giro idiomático semejante al que aparece frecuentemente (con lámed aseverativo o precativo) en A.B. y (sin la lámed) en Arameo Oficial ${ }^{11}$.

Lín. 8

... un escarmiento, el escriba puso primero la palabra פרען nombre masc. sing. en estado absoluto, que significa: «pago», «retribución», y «castigo» y «venganza»; pero después, sin corregir la grafía de la nûn

10 G. R. Driver, Aramaic Documents of the Fifth Century B.C. (Osnabrück 1968), letter 9,3, lee dálet en vez de la más probable rêšs.

11 Cf. Driver, Aramaic Documents, letter 4,3. 
final, añadió la terminación correspondiente al nombre abstracto fem. sing. en estado enfático.

Fitzmyer publicó este texto de forma resumida en su Manual ( ${ }^{\circ}$ 59, pág. 160): línea 1 seguida de la primera palabra de la línea 2, última palabra de la línea 2 seguida de la línea 3 (con la lectura ומתל ארזין), última palabra de la línea 5 (con la lectura ואם (וíneas 6, seguida de las y primera palabra de la línea 8 .

\section{BAR KOSIBA}

Es una carta que referida al transporte de mercancías y personas. Aunque el estado general del documento es bastante bueno, hay muchas lecturas dudosas por la dificultad de entender la grafía. Además, lo conciso de los mensajes y lo impreciso de algunos términos complican extraordinariamente la correcta inteligencia de este texto.

Está en escritura «judía» cursiva, muy rápida y peculiar sobre papiro.

V Bar Kosiba $=$ Yad $56=$ Fitzmyer 58.

\section{Traducción}

Šim 'ôn, hijo de Kôsibah a Yěhônatan, hijo de Be/a'yan,

a Masabalah, y (a) Bar Hyth: Hermanos míos ¡Paz! Reunid

lo que habéis de transportar y los jóvenes con los que vosotros (lo) haréis venir, pero el castigo no será (asunto) vuestro ${ }^{12}$, pues yo

voy a $\operatorname{ser}^{13}$ el que castigue adecuadamente a los romanos ${ }^{14}$. Daréis transporte
Texto

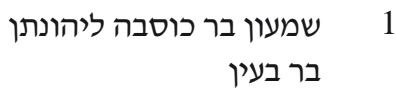

\footnotetext{
12 Lit. «de vosotros».

${ }^{13}$ Otra posibilidad, «yo seré».

${ }^{14}$ Otra posibilidad, «el que castigue, pero vosotros habéis de traer a los romanos» 


\section{Traducción}

a Teodosio ${ }^{15}$, hijo de Teodoro, y él vendrá

con vosotros, ya que lo necesitamos.

Vosotros reunid(lo) (todo).

Acerca de la sal, que no se os vaya de las manos ${ }^{16}$

y (que) hagáis el transporte con mulas, como [no]rmalmente.

¡Seguid bien!
Texto

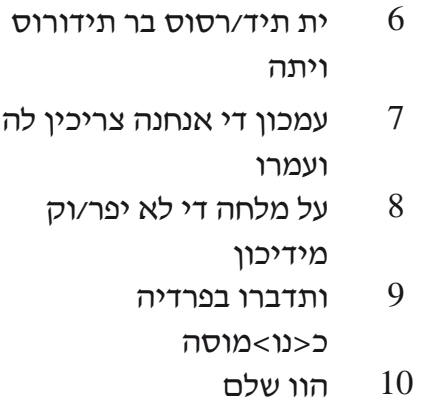

\section{Comentario}

Lín. 1

Kôsibah, con grafía sámek y hê’.

Lín. 2

a Masabalah, lit. «y a Masabalah», con sámek y hề.... y (a) Bar Hyth, no sabemos cuál sería la vocalización de este apellido, pero podría tratarse de un nombre de oficio, «sastre», hayyât ${ }^{17}$. De ser así, Bar Hayyâtâh sería, literalmente, «el hijo del sastre». Aunque aquí no consta su nombre completo, puede tratarse del 'El'azar ben 'El'azar ben Hyṭh, conocido por un documento legal (Yad 44) en hebreo ${ }^{18}$. En nuestro II Bar Kosiba (= Yad 50) aparece un 'El'azar bar Hṭth que acaso sea la misma persona, si es que se ha producido la sorprendente pérdida de la yod intervocálica, lo que es rarísimo en el esquema gramatical de un nombre de oficio, pero que es relativamente normal en los gentilicios y los numerales ordinales terminados en - $\hat{a} y$, cuando reciben sufijos חיטה en su flexión. Lo que en hipótesis podría haber ocurrido, sería

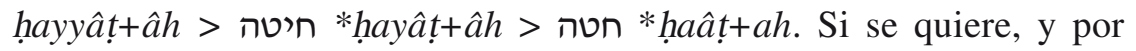

${ }^{15}$ Otra posibilidad, «Tyrso»

${ }^{16}$ Lit. «que no se separe/salga de vuestras manos»

17 Para este supuesto nombre de oficio, $c f$. el arabismo castellano «alfayate» < 'alhayyât. Nótese, además, la terminación - ah, que es el sufijo de estado enfático o artículo arameo, escrito con mater lectionis hêe, como es habitual en el dialecto judeo palestinense.

$18 C f$. YADIN, The Documents from the Bar Kokhba Period, págs. 43-45. 
poner como ejemplo otro nombre de oficio, que también se usa como apellido, y es más conocido, sería algo tan sumamente extraño como si en dayyân, «juez», se hubiese dado la siguiente evolución: dayyân $>$ *dayân > *daân; pero, con todo, no deja de ser significativo que el famoso sitio arqueológico de Galilea llamado Tel Dan, por el nombre de la tribu de Dan, haya sido traducido al árabe como Tell el-Qâḍi, es decir, «La Colina del Juez». Se diría que entre los galileos el viejo topónimo hebreo fue mal interpretado como Dan $<*$ Daan $<*$ Dayan $<$ Dayyân (Juez). Reunid, hemos traducido así el verbo ' $m r$, que es muy rico en significados, en qal significa «permanecer en un sitio», «estar en él», «afincarse», «instalarse», en forma $p a^{\prime} e l$, «recolectar», «reunir» (en especial, reunir plantas de trigo o de otros cereales en gavillas, atarlas y apilarlas unas contra otras en el campo para que se sequen hasta que llegue el momento de la trilla).

Lín. 3

y los jóvenes, la lectura no es muy clara, pero parece que nos encontraríamos con un sustantivo masculino 'lym en estado enfático. Este vocablo también es rico en significados: 1) «fuerte» «vigoroso», 2) «joven», «muchacho»3) «sirviente», «esclavo» 4) «guerrero joven», «recluta», «escudero»...(cf. en hebreo ná'ar). Este sustantivo es el antecedente de una oración de relativo con pronombre retrospectivo [lit. «y los jóvenes que vosotros (lo) haréis venir con ellos»-sic-]. Parece, pues, que estos «jóvenes» tendrían que llevar algo reunido en En-Guedi hasta el frente, donde se encontraría el cuartel general del remitente de la carta. Como a continuación se habla de «un castigo a los romanos», se nos plantea la duda de si estos «jóvenes» tienen alguna relación con los castigos y los romanos después mencionados. Si la respuesta es que no tienen nada que ver, se pondría un punto y seguido al final de la línea 3 , y no se traduciría la conjunción copulativa con la que comienza la línea 4. Pero si, como nosotros suponemos, hay alguna relación entre estos «jóvenes» y lo que viene a continuación, las posibilidades son otras. Se podría pensar que esos «jóvenes» eran «reclutas» y que lo que debían transportar y hacer llegar a Bar Kôsiba eran precisamente «los romanos» que habrían de ser castigados. Otra posibilidad sería que esos «jóvenes» no fuesen judíos, sino «cautivos» o prisioneros de guerra tomados a las tropas romanas que, concentrados primero en En-Guedi, serían obligados más tarde a realizar un transporte y a ir al frente para 
que se hiciese de ellos un público castigo. En cualquiera de estos casos convendría traducir la conjunción copulativa vav con la que comienza la línea 4, y mejor hacerlo como una conjunción adversativa, «pero», que como una causal, «pues».

Lín. 4

pero, lit. «y»;... el castigo no será (asunto) vuestro, lit. «de vosotros». Nuestra traducción difiere de la de Yadin: ${ }^{19}$ "so that there will be no punishment (exacted) from you», al igual que discrepamos en nuestro II Bar Kosiba = Yad 50, líneas 11-12, donde puede encontrarse más información.

Lín. 5

.. voy a ser/seré el que castigue..., no está claro si nos encontramos con una preformativa mem de participio de forma derivada, en este caso 'itpe. o 'itpa., o con una preformativa 'álef de imperfecto de la misma forma. Nuestra primera opción sería la de considerarlo un participio que, por ser atemporal, se podría traducir por nuestro futuro, igual que si fuese un imperfecto. Con todo, para señalar en traducción las dos posibilidades hemos recurrido a traducir el participio por una perífrasis y el imperfecto por un futuro. La raíz del verbo es $p r^{c}$, en forma 'itpe. o 'itpa., además de «ser pagado», «ser remunerado», significa «ser vengado», «tomar venganza» $\mathrm{y}$ «castigar».

... adecuadamente/pero vosotros habéis de traer..., la lectura no está clara y se apuntan estas dos posibilidades. ... los romanos, rhvmyh, nombre gentilicio masculino enfático con mater lectionis hề que hemos interpretado como un plural (rhômâyê), podría ser también un singular (rhômâyâ).

Lín. 6

... y él vendrá, imperfectivo del verbo אתה con pérdida de la primera radical.

Lín. 8

... que no se os vaya de las manos, lit., «que no se separe/salga de vuestras manos». La lectura es difícil, pero aunque haya dos posibilidades para el verbo, el sentido parece ser el expresado por la coloquial expresión castellana «irse de (o de entre) las manos».

${ }^{19} C f$. Yadin, The Documents of the Bar Kokhba Period, pág. 319. 
Lín. 9

... con mulas, la lectura no es clara, pero esta parece ser la mejor opción... como [no]rmalmente, parece ser la palabra griega nómos, «costumbre», «norma», «ley»...

Las siguientes partes de este texto fueron publicadas en el Manual de Fitzmyer, n 58 , pág. 160: la línea 1 completa y sin variantes, dos únicas palabras de la línea 5: רהומיה y ותדברון (ת) la línea 6, con la lectura: «Tirsis, hijo de Tininos» (תירסיס בר תינינוס), y la línea 7, excepto la última palabra. Parte de la línea 9, pero con una lectura discrepante: «nuestro jefe (o rabino) Betenyah, hijo de Misa» (רבנו בטניה בר מיסה), y, finalmente, las dos palabras de la línea 10 , ya sin variantes.

\section{BAR KosIBA}

Es una carta muy deteriorada referida al transporte de sal. Escritura «judía» cursiva estándar sobre papiro.

VI Bar Kosiba $=$ Yad $58=$ Fitzmyer 57.

\section{Traducción}

[De] Šim[']ôn a Yonatan (sic) y Maśabalah

¡Salud! Reuniréis y enviaréis a los

campamentos

cargas de sal (en numero de) cuatro. ¡Sigue bien!

¡[Y] (¿lo mismo?) a los hombres de Qiryat 'Arbayyah!

\section{Texto}

$$
\begin{array}{r}
1 \\
2 \\
\\
\end{array}
$$

\section{Comentario}

\section{Lín. 1}

Yonatan, aquí el nombre de «Yěhônatan» aparece extremadamente acortado. Maśabalah está escrito con grafía sîn, aunque Fitzmyer ponga sámek 
Lín. 2

Reuniréis... este verbo va precedido del pronombre relativo aislado $d \hat{\imath}$ en función de partícula introductoria. Véase más arriba el comentario a I Bar Kosiba = Yad 53, lín. 2. Nótese además la terminación -ûn, con scriptio plena, de la segunda persona masculino plural del imperfecto de indicativo de este verbo, mientras que en el verbo siguiente $-y$ enviaréis - se emplea la scriptio defectiva para la misma terminación. La terminación en -ûn, con scriptio plena en el primer verbo nos parece segura, aunque Fitzmyer 57 la pone como defectiva. Asimismo, Fitzmyer considera que el verbo no es de raíz ' $m r$, sino de raíz $n m r$, «cosechar o recolectar selectivamente», y da la lectura תנמרן, que se traduciría por «cosecharéis» (You are to reap), en lo que nosotros tampoco estamos de acuerdo. ... a los campamentos, se trata de un plural masculino enfático con mater lectionis hề. Aunque podría ser un calco semántico del plural latino castra, «campamento militar», y cabría traducirlo en singular, hemos optado por mantener en la traducción el plural.

Lín. 3

cargas, la lectura presenta dificultades por el mal estado de conservación del papiro, pero parece ser un plural masculino con scriptio defectiva del sustantivo טעון, «carga».... de sal, a pesar de que también aquí el papiro está muy deteriorado, son reconocibles los trazos característicos de todas las letras de la palabra מלח, «sal». ...jSigue bien! La fórmula de despedida está en singular aunque el mensaje va dirigido a dos personas y cabría esperar el plural ¡Seguid bien!

Lín. 4

i[Y] (¿lo mismo?) a los hombres de Qiryat 'Arbayyah! Esta extraña frase que viene tras la fórmula de despedida, y con la que concluye el mensaje, se suele interpretar como una posdata para extender aquellos mismos buenos deseos a las gentes de la ciudad mencionada.

Este texto fue publicado en el Manual de Fitzmyer (nº 57, pág. 160), pero sólo las líneas 1 y 2 , y con las variantes que ya hemos indicado en nuestro comentario. 


\section{BAR KosIBA}

Es una carta extraordinariamente deteriorada referida, al parecer, a un pago. Partes del soporte de la escritura han desaparecido y en muchos lugares sólo se conservan letras aisladas que no permiten la reconstrucción de palabras concretas, por lo que en nuestra edición ni siquiera las anotamos.

Escritura «judía» cursiva estándar sobre papiro.

VII Bar Kosiba = Yad 63 = Fitzmyer 54.

\section{Traducción}

De Šim ôn, hijo de Kôsiba' a [Yěhônatan y Maśaba]lah. Que

.$^{20}$

y pagados que... ${ }^{21}$

y todo... ${ }^{22}[\ldots]$ yo os he escrito

a vosotros y os he enviado la carta por [me]dio de Šim'ôn,

hijo de Yišma"el. No hag[áis]

a ...

$\ldots^{23}$

... que (¿?) ¡Se[guid b]ien!
Texto

1

ד

....[ ] ]..... [ ]

3

4

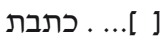

5 5 5

6

..... ] ] ] ב [ ]

...[ ] ].... [ ] ]... 7

[ ] ]...[ ]

8

[en blanco]

\footnotetext{
${ }^{20}$ Sólo se conservan letras aisladas que no permiten identificar palabras concretas

${ }^{21}$ Sólo se conservan letras aisladas.

${ }^{22}$ Sólo se conservan letras aisladas.

${ }^{23}$ Sólo se conservan letras aisladas.
} 


\section{Comentario}

\section{Lín. 1}

Kôsiba' con sámek y mater lectionis final 'álef.

Lín. 3

y pagados, literalmente, «y pesados», una expresión habitual para indicar que se ha realizado un pago. Alude a la antigua práctica de pesar los metales preciosos, costumbre que se mantuvo incluso en la época en que esos metales ya circulaban amonedados.

Fue publicado en el Manual de Fitzmyer ( $n^{\circ} 54$, pág. 158), pero sólo la línea 4 y las tres primeras palabras de la línea 5, así como la siguiente lectura de parte de la línea 6: [ואם] לא תעבד]ון], «and if you do not do [so]», es decir, «y si no lo hacéis [así]».

\section{BAR KOSIBA}

Esta carta se encuentra tan sumamente deteriorada que, de lo que parecen ser cuatro líneas de escritura, sólo se ha podido proponer la lectura de una única palabra al principio de la segunda mitad de la línea cuarta. De las otras líneas, sólo se han podido proponer la lectura de letras sueltas que no permiten identificar palabras concretas.

La escritura parece ser cursiva «judia» estándar. El soporte es un papiro en muy deficiente estado de conservación.

\section{Bar Kosiba = Yadin 62.}

\section{Traducción}

.. como... ${ }^{24}$
Texto

${ }^{24}$ Sólo se conservan letras aisladas. 


\section{Comentario}

\section{Lín. 4}

como... Se trataría de un adverbio arameo de modo que podría traducirse, además (dependiendo de un contexto que nos falta) por «así como», «igualmente», «del mismo modo»...

No fue publicado en el Manual de Fitzmyer.

\section{BAR KosIBA}

Se trata de la muy famosa carta de «las cuatro especies» o clases de productos vegetales necesarias para la celebración de la fiesta de Sukkôt (Tabernáculos) o «Pascua de las Cabañuelas», esto es: «palmas, cidras, mirtos y sauces».

La carta va dirigida a un tal Yěhûdah bar Menaššeh, que se encuentra en Qiryat 'Arbayyah. Se trata, pues, de una persona distinta de los habituales Yěhônatan bar Bela'yan y Masabbalah, de En-Guedi. Ahora bien, como la misma carta indica, al primero se le ordena hacer una gestión ante los segundos, y esa sería la razón de que Judas les remitiese esta carta que, a la postre, se quedaría entra la documentación de Yěhônatan y Masabalah que ha llegado hasta nosotros.

Por lo interesante de su asunto y por su sencillez relativa nos ha parecido que debe ser el texto que cierre nuestra serie de las cartas de Bar Kosiba.

Está en escritura cursiva «judía» estándar sobre papiro.

$$
\text { IX Bar Kosiba }=\text { Yad } 57=\text { Fitzmyer } 60 .
$$

\section{Traducción}

Šim'ôn a Yěhûdah, hijo de Menaššeh, a Qiryat 'Arbayyah. Te he mandado dos asnos con los que tú enviarás

\section{Texto}

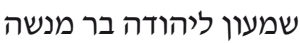
לקרית ערביה שלחת לך שיח משרח תרי חמרין די תשלח שלחת ליח 


\section{Traducción}

un par de hombres a Yěhônatan,

hijo de Be/a'yan y a Masabalah, los cuales recolectarán

y mandarán a los campamentos, a ti, palmas y cidras. Tú envía

a otros de junto a ti,

y que te consigan mirtos y ramos de sauce.

Dispónlos y envíalos

a los campamentos, ya

que el personal es numeroso. ¡Sigue bien!
Texto

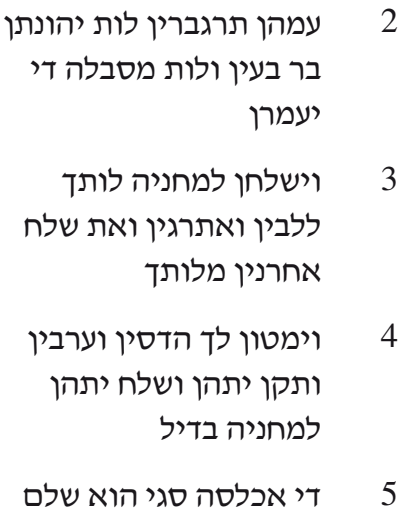

\section{Comentario}

\section{Lín. 1}

El remitente, Šim 'ôn no indica aquí su apellido. El topónimo Qiryat 'Arbayyah, si nuestra restitución vocálica es correcta se podría traducir por «La ciudad de los sauces» o «La Sauceda», lo que justificaría que se recurriese a esa localidad para obtener los ramos de sauce (y los mirtos) requeridos para la fiesta de Tabernáculos (Sukkot). Cada uno de los dos asnos, a poco buenos que fuesen, tendría una capacidad de carga en distancias cortas de unos $45 / 50 \mathrm{~kg}$.

\section{Lín.2}

un par de hombres, תרגברין-sic-junto en vez de גברין תרי - גו

Lín. 3

a los campamentos, plural masculino enfático con mater lectionis hề, y lo mismo en la línea 4, podría tratarse de un calco semántico del plural latino castra $=$ «campamento militar» $($ sing. castrum $=$ «fuerte», $«$ plaza fuerte»). Aquí se trata del acuartelamiento de Qiryat 'Arbayyah, pues se concreta al decir «a ti (a Yěhûdah bar Menašš h)», pero en cambio los otros «campamentos» que se mencionan después, en la línea 4, serían los cuarteles del remitente, Šim 'ôn (bar Kosiba). 
Lín. 4

Dispónlos, el verbo empleado tqn en la forma $p a$. es muy rico en significados, y aquí además de «disponer»o «preparar», podría tener el sentido más preciso de «retirar el diezmo religioso»o «diezmar», de modo que, al ser deducido en origen el impuesto religioso, se pudiese utilizar por parte de Bar Kosiba la totalidad del envío.

Lín. 5

el personal, אכלסה, es un préstamo griego 'ókhlos, «el gentío», «la muchedumbre», al que se añade la terminación de enfático singular con mater lectionis hề'. En arameo targúmico 'ôk $k l o \hat{s} \hat{a}$, suele aparecer en plural 'ôklôsîn. En הוא שלם (hve' šlâm), «iSigue bien!» la mater lectionis es 'álef, pero la misma fórmula aparecía con la mater lectionis $h \hat{e}$ ' en I Bar Kosiba = Yadin 53.

Este texto es el publicado con el $n^{\circ} 60$ en la pág. 162 del Manual de Fitzmyer, pero encontramos las siguientes variantes: Fitzmyer en lín. 4 lee הדססון, en vez de הדסין. Asimismo, ha omitido la frase ........ al final de la lín. 4 y principio de la lín. 5. 


\section{RESUMEN}

En este artículo ofrecemos la edición y traducción al castellano del corpus completo de las cartas de Bar Kokbba escritas en lengua aramea, y que fueron descubiertas a mediados del pasado siglo XX. La traducción viene acompañada de un amplio comentario filológico para aclarar algunas de las discrepancias que mostramos con las traducciones ya existentes de los textos. El artículo también contiene una introducción sobre la historia del descubrimiento y características lingüísticas del arameo de las cartas.

Palabras Clave: Bar Kokbba, arameo, cartas arameas.

\section{SUMMARY}

We offer in this article the edition and Spanish translation of the whole corpus of the Aramaic Bar Kokbba letters, discovered in the middle years of the last century. The translation and edition is followed by a grammatical companion that explains the editorial choices and differences with respect to previous scholarly works. Besides, we add a brief history of the discovery and a grammatical compendium of the Aramaic language of the letters.

KeYwords: Bar Kokbba, Aramaic, Aramaic letters. 